\title{
Novel hydraulically relieved electromechanical direct actuation system for large scale switching valves
}

\author{
Tobias Vonderbank*, Pierre Marc Laß1 Chavez, Katharina Schmitz
}

Institute for Fluid Power Drives and Systems, RWTH Aachen University, Aachen, Germany E-mail: tobias.vonderbank@ifas.rwth-aachen.de*

\begin{abstract}
Extensive actuation forces and strokes are required for the actuation of large sized valves normally implemented in high power hydraulic systems. A hydraulic piloted operation is, as for now, the most suitable solution and the state of the art. However, recent research has shown that the application of new electromechanical valve actuation systems is possible in various cases. In this contribution a novel electromechanical valve actuation system for large sized 4/3-way directional control valves in a displacement controlled system is presented. The new actuation system is characterized by a hydraulic relief of the centering springs. Therefore, the springs are only active in safety-critical conditions, as in a power outage. Since the actuator is not working against the spring force during every displacement, the necessary actuation force is reduced drastically, so that common electromechanical actuators can be used. In case of a power outage, the spring relief is deactivated causing the stored energy to center the spool in neutral position. The performance of the novel actuation system is examined based on measurements, which are conducted on a manufactured demonstrator for valves of nominal size 25 with a flow rate of up to $600 \mathrm{l} / \mathrm{min}$.
\end{abstract}

Keywords: Electromechanical actuation system, Large sized valves, Valve actuation system, Pilot operation, Flow controlled system

\section{Introduction}

Directional control valves are used to open or close flow paths of hydraulic systems [1-3]. Valves can be distinguished in their design (spool or seat valve), their adjustment (switching or proportional) and their actuation system [2]. To ensure the interchangeability of different valves the International Organization for Standardization has defined the dimensions and other specifics for mounting surfaces of four-port hydraulic directional control valves in the ISO 4401 [4]. This standard specifies six different nominal sizes with corresponding mounting surfaces which are distinguished by the position of the port holes and their maximum diameter. For industrial valves it is common practice that valves are classified by their respective nominal size.

The mounting surface for valves of nominal sizes 4, 6, 10, 16, 25 and 32 correspond to the six surfaces defined in ISO 4401. Valves of large nominal sizes possess higher possible port diameters and therefore allow for higher flow rates to develop. This correlation can be seen in Figure 1. The maximum possible flow rate of a specific valve series is displayed over the corresponding nominal size. Since the cross-section increases quadratically with the increment of the port's inner diameter there is, under assumption of a constant maximum flow velocity, an approximately quadratic progression between the nominal size and the maximum flow rate. 


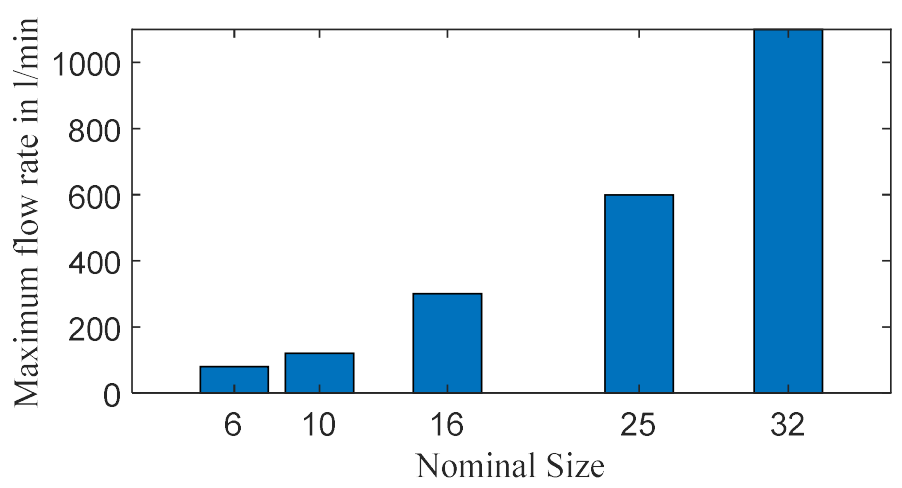

Figure 1: Maximum flow rate of a specific valve series over their nominal size. Data from [5]

Spool valves with a maximum flow rate larger than $80 \mathrm{l} / \mathrm{min}$, which in practice are usually valves of nominal size 16 and larger, are normally actuated by a hydraulic pilot valve [1]. The performance of the whole actuation system depends on the pilot valve's hydraulic supply. Therefore, special attention must be paid to its design when using pilot operated valves. The pilot circuit can be supplied internally or externally by a separate hydraulic circuit. An external supply is essential for a faultless operation if pressure in the main line is able to drop below a critical value. In the literature, reference is made of a necessary minimum pressure of around 4 to 5 bar $[1,6]$. The simplest external pilot supply consists of a fixed displacement pump supplying the pilot valve with a constant flow rate. Even if an improvement in efficiency through more complex pilot circuits is possible a trade-off between efficiency and expense must be made. Another way to potentially increase the efficiency is the application of electromechanical actuators, which represent a cost-effective alternative to hydraulic pilot systems. However, the necessary forces and large strokes which are required for larger valves to operate are challenging for common electromechanical actuators, like solenoids. During the movement of the spool, the actuator has to overcome various counter forces, as shown in Figure 2.

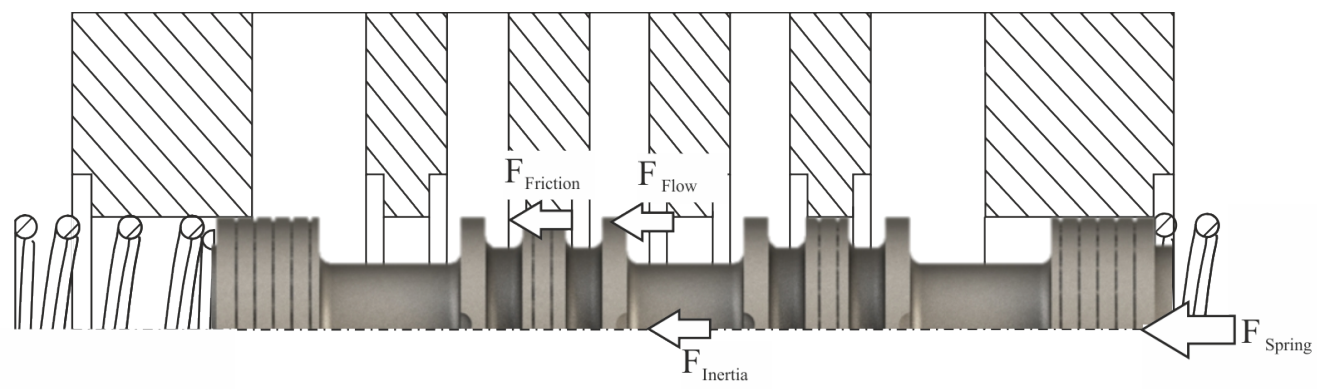

Figure 2: Applied forces on the spool according to. [7-11]

In the case of large valves, the most relevant forces acting during actuation are the flow and the spring forces. For valves with nominal size 25 , previous research has shown that flow forces can reach values up to $800 \mathrm{~N}$. Under operation in a flow-controlled system, a directional control valve faces considerably lower flow forces, when the flow rate of the system is reduced before the valve is switched. The observed reduction in flow forces results from a limited differential pressure and flow speed during valve switching. Due to the reduction of the occurring forces it is precisely in these systems that the implementation of electromechanical actuators is feasible and therefore an external pilot circuit would no longer be required.

The spring force represents the largest forces besides the flow forces. In 4/3-way directional control valves their function is to center the valve in the middle position anytime. Actuation systems that are capable of actively assume the center position could, in principle, leave out the spring centering. However, the springs fulfil a safety function, and are therefore necessary in the event of a power outage.

Aiming to reduce the necessary forces and therefore make the application of common electromechanical actuators possible an electromechanical actuation system is investigated in the following. It consists out of common solenoids and a hydraulic spring relief system, which is used to compress the springs during normal operations. Since the spring forces only act in case of failure, the driving electromechanical actuators only need to overcome friction and inertia related forces. In the case of a power outage, the spring relief system is deactivated, causing the springs to center the spool and fulfil the safety requirements. 


\section{Design of novel hydraulically relieved electromechanical direct actuation system for large scale switching valves}

\subsection{Principal design}

Large forces can be easily applied with hydraulic linear actuators [3, 6, 12, 13]. Therefore, the pilot operation is suitable for the actuation of linear movement tasks with high forces over large strokes as in the actuation of large sized valves. In contrast to this, the functional structure of a common electromechanical valve actuation system of direct operated valves is depicted in Figure 3. Used are the symbols of elementary functions according to Table 1.

Table 1: Symbols of elementary functions in accordance with

\begin{tabular}{|l|l|}
\hline & separate/connect energy flow \\
\hline & convert energy flow \\
\hline
\end{tabular}
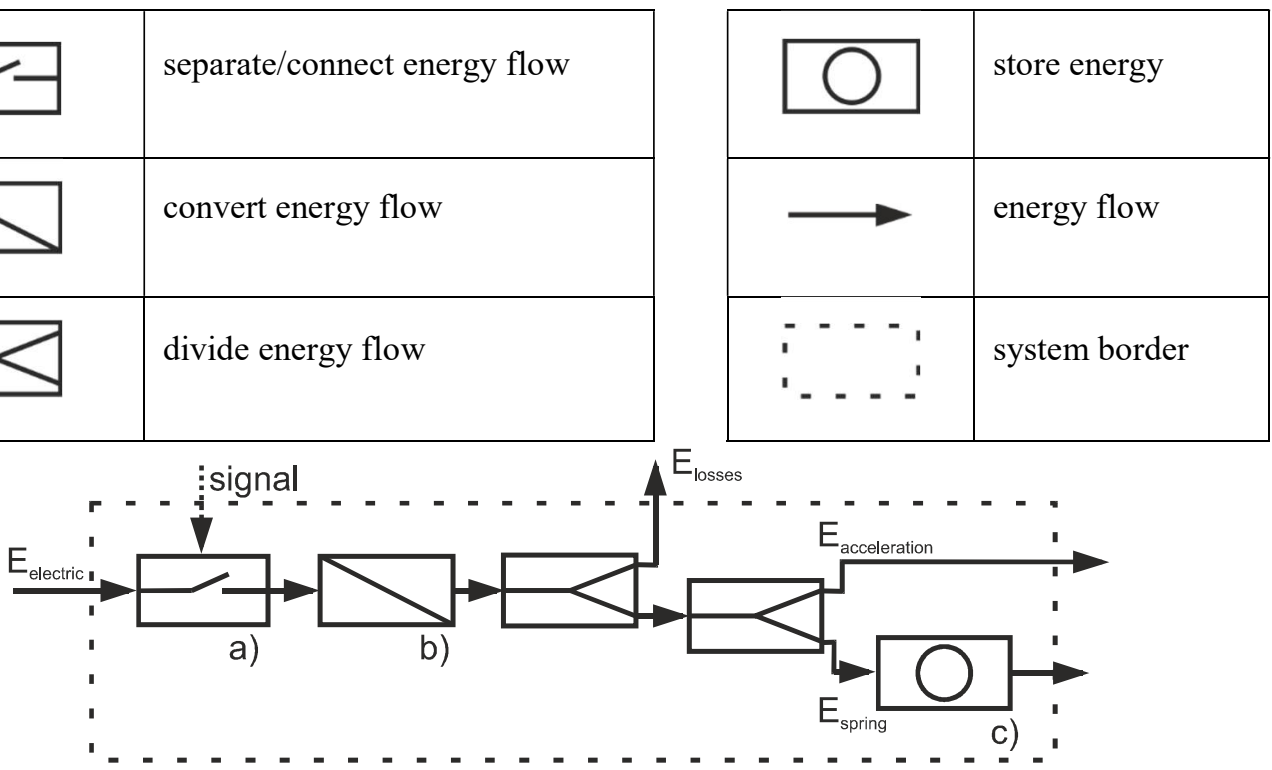

Figure 3: Functional structure of a common electromechanical valve actuation in accordance with [14]

The actuation system consists of a switch a) and an electromechanical transformator b), which converts the electric energy $E_{\text {electric }}$ into mechanical energy. Subtracting the losses $E_{\text {losses }}$ due to friction and other resistance forces, the remaining energy is transmitted to the spool and transformed into kinetic energy resulting in an acceleration of the spool. During the movement, a large part of the applied energy is stored in the springs $\left(\mathrm{E}_{\text {spring }}\right)$, which work as accumulator for mechanical energy c). This energy is always applied on the spool and the spring force tends to accelerate it in closing direction. Therefore, two mechanical energy paths are leaving the system. If the actuator is deactivated, the stored spring energy will cause the spool to center in middle position. In order to keep the spool deflected, the actuator must thus always apply a greater force to counteract the spring force. The functional structure is extended by a second branch representing the spring relief system as shown in Figure 4 . If the spring is loaded by another actuator, the electromechanical transformator b) only needs to bring up the energy $E_{\text {losses }}$ to overcome the friction and resistance losses and $\mathrm{E}_{\text {acceleration }}$ to accelerate the spool in a sufficient time. This allows not only the downscaling of usable electromechanical actuators, but also the use of previously unsuitable electromechanical transformators.

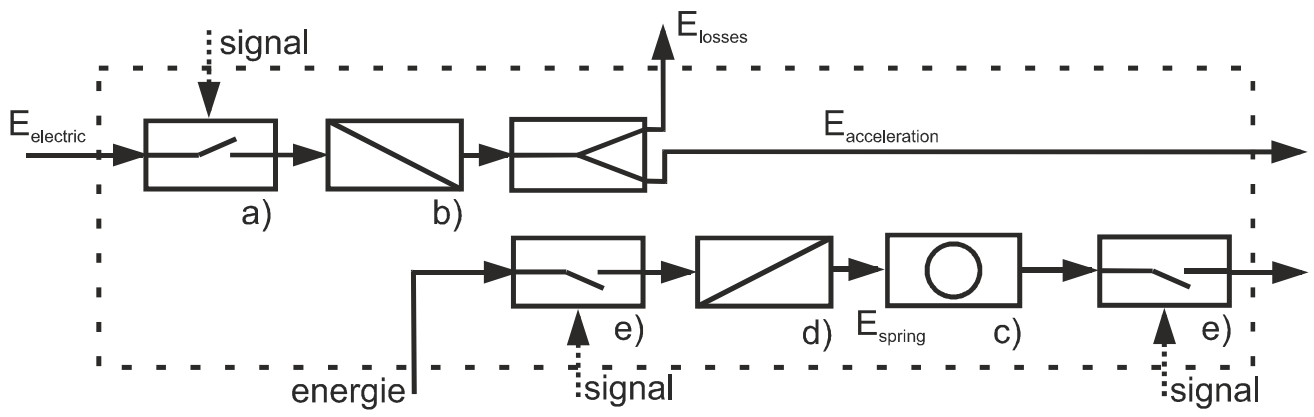

Figure 4: Functional structure of a spring relieved actuation system 
The spring relief system, which is depicted in the lower branch of the functional structure, consist of two switches e), an energy transformator d) and the spring c). The switches e) serves to control the charging and discharging of the spring c). The spring c) can be charged with an alternative energy supply since the acceleration of the spool and the compression of the spring no longer happen simultaneously.

This concept of divided energy supply was realized in form of a hydraulically relieved electromechanical actuation system, which is sketched in Figure 5 and Figure 6. The actuation system is designed for a 4/3-way directional control valve of nominal size 25 , which is implemented in a flow-controlled system. The design is able to apply higher forces than initially required, in order not to be completely limited to the application described in the introduction. Therefore, the actuator can also switch the valve under certain load.

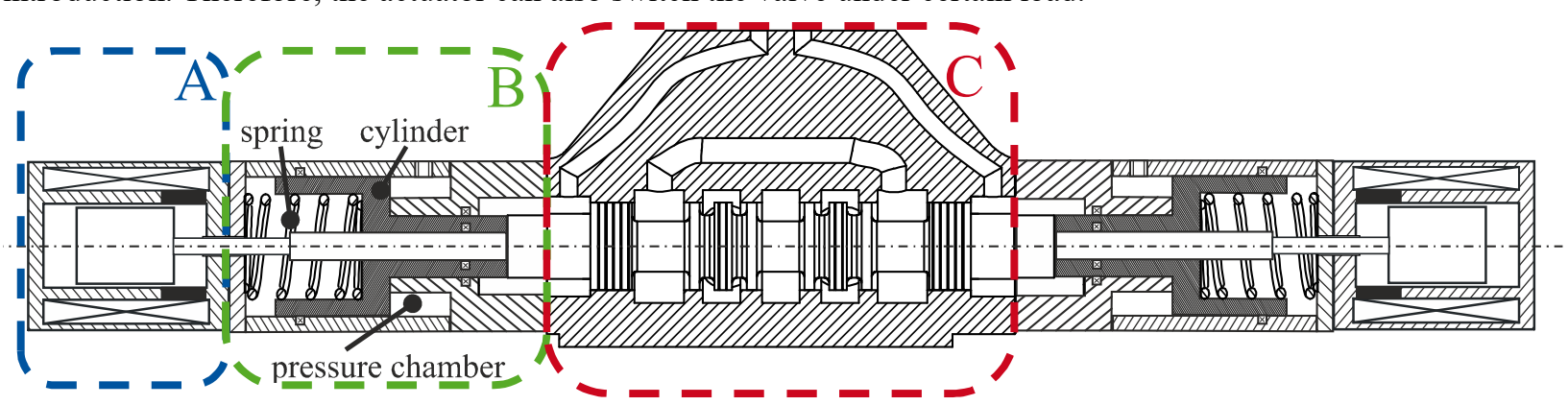

Figure 5: Technical sketch of the novel electromechanical actuation system. Spring relief not active.

The actuation system can be divided into three essential components. The component A represents a solenoid, which translates the electrical into mechanical energy. The hydraulic spring relief system B is located next to the solenoid. It is attached on both sides of the valve's housing C. To realize an active centering of the spool in neutral position a third solenoid is required, which is not sketched in. The hydraulic spring relief system depicts a spring returned cylinder in B, which centers the spool in case of a power failure. If the pressure chamber is pressurized, the cylinder will compress the spring until reaching the hard stop of the housing. Since the spool and the relief cylinder do not have a mechanically fixed connection, a gap is created between these two components. The spool is floating. This relieved state is shown in Figure 6.

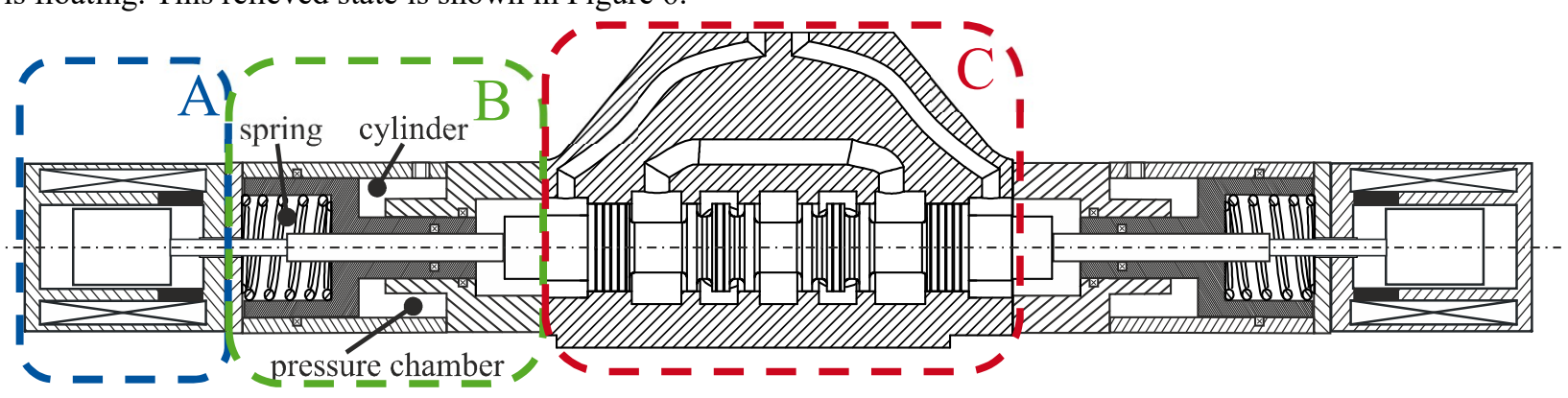

Figure 6: Technical sketch of the novel electromechanical actuation system in hydraulic relieved state

A rod, which connects the solenoid to the spool, is guided through the relief cylinder to transmit the force mechanically. In case of a power failure, the pressure chambers are relieved against the tank causing the spring to displace the relief cylinder. Thereby the spool also is centered in the middle position.

\subsection{CAD of novel hydraulically relieved electromechanical direct actuation system for large scale switching valves}

This new concept for a hydraulically relieved electromechanical direct valve actuation system was designed as a CAD model and was subsequently manufactured. The 3-D Modell is shown in Figure 7. To place the focus on the central aspect of the actuation system, namely the hydraulic relief system, the solenoids are not depicted. A hydraulic spring relief system is attached on each side of the 4/3-way directional valve. 


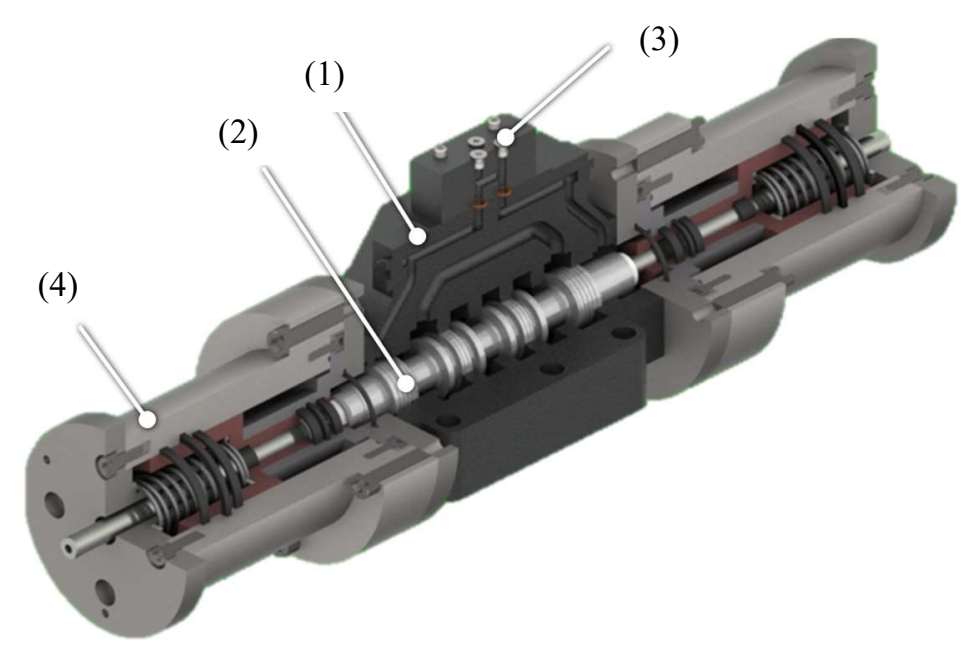

Figure 7: 3D-CAD model of the hydraulically relieved actuation system

The assembly consists of a valve housing (1), a spool (2) an adapter plate (3), which short circuits the pilot chambers to each other with an additional drain line to the tank, and two spring relief systems (4). This assembly is shown in detail in Figure 8. The hydraulic relief chamber (4.1) is formed by the housing (4.2), the relief cylinder (4.3), the spring (4.4) and the force cylinder rod (4.5). The connection port (4.6) represents the system's connection to the hydraulic system which will be explained in chapter 2.3 .

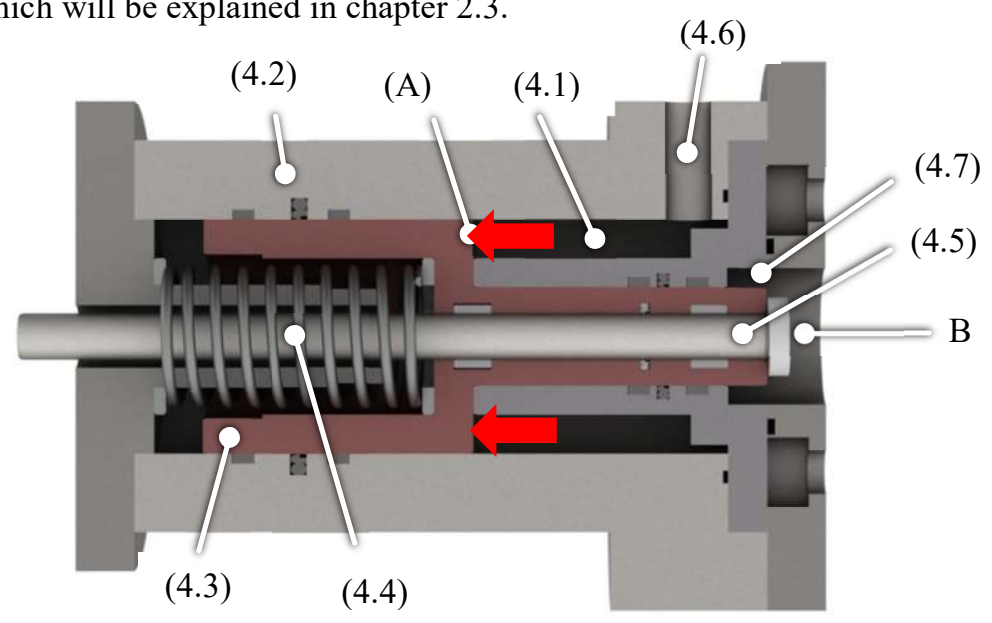

Figure 8: CAD model of the pressure relief system

Pressure builds up and acts on the area A of the relief cylinder (4.3) during the pressurization of the relief chamber (4.1). If the resulting force is larger than the preload force of the spring (4.4), the relief cylinder will be deflected and the spring will compress. The spool is not centered by the relief cylinder and can be moved freely. If the relief chamber is depressurized, the energy stored in the spring (4.4) will accelerate the relief cylinder (4.3) in closing direction. The stored energy must be sufficient to overcome all resistance forces, like friction or system inherent hydraulic resistance forces and accelerate the relief cylinder (4.3) fast enough to center the spool in sufficient time $[9,10]$.

During the reset of the process, fluid is displaced through the connection port (4.6) out of the relief chamber (4.1) and drained into the tank. As a result, a pressure difference between the chamber and the tank builds up, which poses a not negligible resistance force. Furthermore, the pressure in the pilot chamber (4.7) is also applied on the surface $\mathrm{B}$, which leads to a further resistance force.

\subsection{System design}

The control of the relief system can be realized by two seat valves $\left(\begin{array}{l}1 \& 2 \\ \text { \& }\end{array}\right)$ arranged in a hydraulic circuit as presented in Figure 9. The control by two seats valves enables the charging and discharging of the relief system as well as the decoupling of the relief circuit from the main circuit. The novel direct electromechanical actuation system is drawn with standardized symbols for hydraulics in accordance with ISO 1219 [15]. The spring relief system can be interpreted as a spring returned cylinder (3), which is mechanically connected through a rod (4) to the spool of the valve. The designed actuation system is driven by three solenoids (5.1-5.3) which are drawn on 
the bottom line of the valve. The solenoid on the left side can switch the spool to position A, the lower solenoid on the right side to position B and the solenoid above that (5.2) to neutral position.

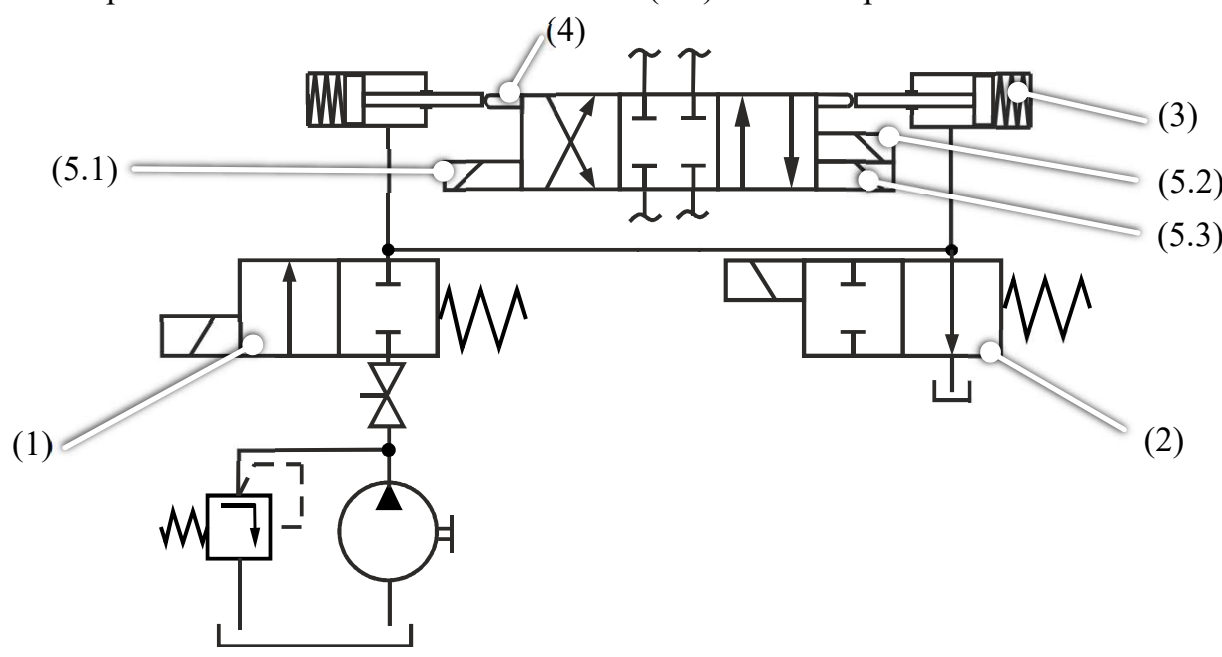

Figure 9 Hydraulic circuit to control the relief system

The solenoids on the right side are arranged with an offset to each other, so that only when (5.2) is energized the spool takes in the centered position. To fulfil a proper safety function, the loading valve (1) needs to be normally closed while the unloading valve (2) needs to be normally opened. To activate the relief system the loading (1) and the unloading valve (2) are energized simultaneously. After the system is initialized the spool is floating and the load valve (1) must be deenergized, so that the relief system is separated from the remaining hydraulic system and only leakage will lead to a pressure change. First measurements have been carried out to demonstrate that the pressure in the relief system does not drop rapidly while active. After the system was fully loaded a ball valve, located between the pump and the loading valve, was closed manually at a time of around 60 seconds. Sequentially the pressure in front of the load valve dropped down to 1 bar. In contrast, the pressure in the relief system could be maintained to nearly the same value for at least two minutes. Exemplary measurement results are displayed over time in Figure 10.

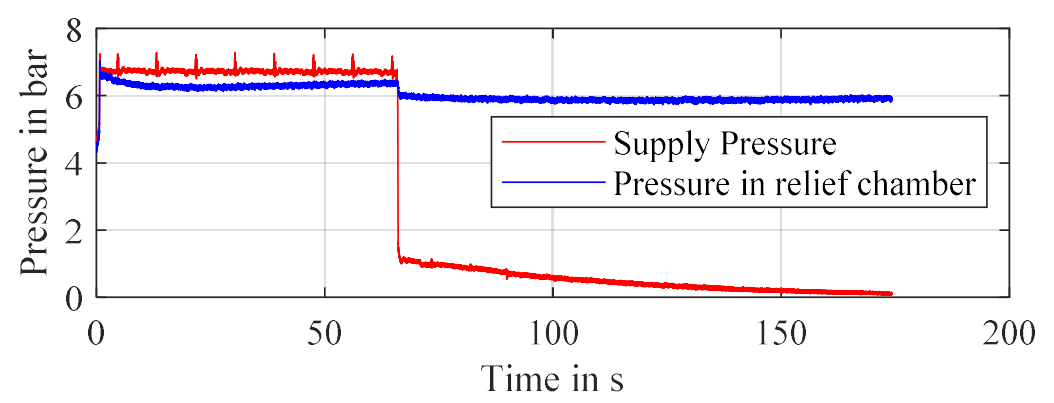

Figure 10: Measurements of the time dependent pressure drop in the designed accumulator

In case of an electrical power outage, the centered position cannot be attained actively by solenoid (5.2) anymore. The spool will remain in the deflected position requiring the relief system to be deactivated. Due to the operation modes (NC/NO) of the selected loading and unloading valve, this will occur automatically as long as the actuators and the relief system are energized by the same power source. In this case, both the loading and unloading valves will deenergize at the same time, causing the relief chamber to depressurize and therefore the springs to decompress. The spool is thereby accelerated to the neutral position, allowing the valve to take in its safe state.

When operating in industrial applications, the operation of the relief system must be adapted to the actual system. The simplest possible system design is shown in Figure 11. In this layout, the relief system is supplied by a separate pump. This system design still requires a pilot circuit and therefore possess no significant advantage against common pilot operated systems. If put in contrast to a hydraulic pilot control, the energy required to accelerate the spool and to compress the springs is no longer provided simultaneously. The compression of the springs can be realized before the switching process. Thereby the relief system can be supplied by the main pump without the possible eventuality that the pressure could drop below a critical value. The relief system can be integrated in the main circuit, as shown in Figure 12. 


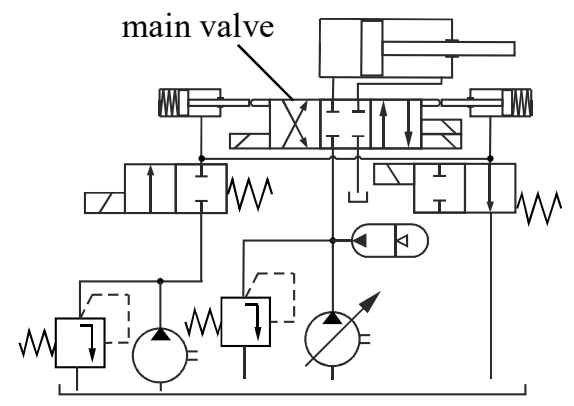

Figure 11: Hydraulic circuit for a new hydraulically relieved actuation system with external supply of the relief chamber

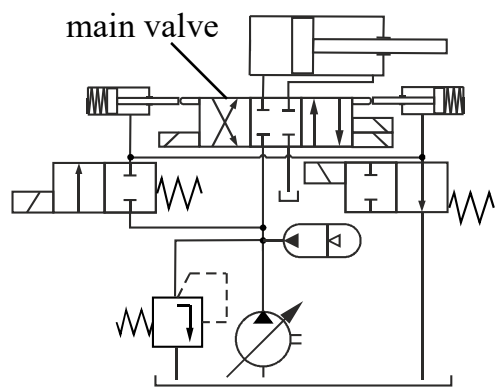

Figure 12: Hydraulic circuit for a new hydraulically relieved actuation system with integrated supply of the relief chamber

The relief system only can be loaded when pressure in front of the main valve is above a sufficient level. Once the main valve is closed, the delivered flow is relieved by the pressure relief valve directly to the tank. The pressure in the main line then is defined by the systems main pressure relief valve, so that maximum system pressure can be guaranteed. This way the relief system can be loaded by a short swing movement of the main pump. If necessary, a pressure reducing valve and a second pressure relief valve can be incorporated to prevent impermissibly high pressures in the relief system.

\section{Experimental results}

A test rig, according to Figure 13, was built at the ifas lab for experimentally testing of the hydraulically relieved electromechanical direct valve actuation system. The main circuit consists of a servo valve (SV), an adjustable pump $\left(\mathrm{P}_{1}\right)$, a pressure relief valve $\left(\mathrm{PRV}_{1}\right)$ and a directional control valve of nominal size $25\left(\mathrm{~V}_{1}\right)$, at which the new actuation system has been attached. Additionally, six pressure sensors $\left(p_{1}-p_{6}\right)$, two temperature sensors $\left(T_{1}\right.$ and $\left.T_{2}\right)$ and a flow rate sensor $(\mathrm{Q})$ has been incorporated into the main circuit. Two displacement sensors record the position of the force cylinder rods (4.5 in Figure 8), whereas five current sensors measure the currents of the three solenoids, as well as the loading and unloading valves. Two additional pressure sensors $\left(\mathrm{p}_{7}\right.$ and $\left.\mathrm{p}_{8}\right)$ have been installed in the relief system circuit. For security reasons and since no burst test could be conducted previously, the power supply of the relief system was realized by an external hydraulic circuit, as shown in Figure 11. After the initial loading of the pressure relief system, its power supply was cut off by a manually operated ball valve. This step was made since beforehand demonstrations showed a reliable holding of pressure over a long period of time in the hydraulic relief system.

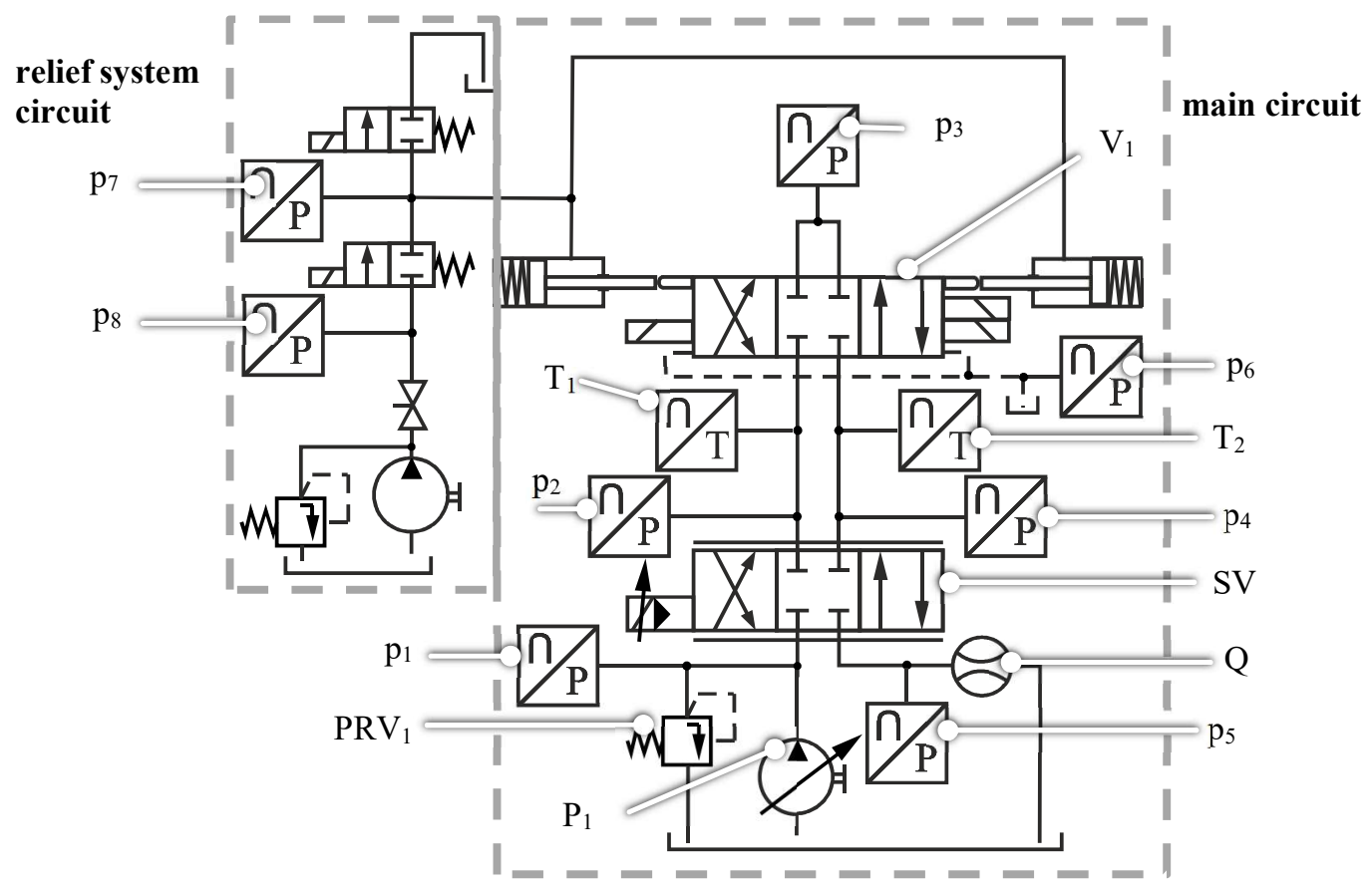

Figure 13: Hydraulic test rig 
Beside the switching and the reset process also the static behavior of the actuation system during high flow phases is interesting, since high flow rates can lead to high flow forces [16-18]. Aiming to investigate these relevant states of operation two test cycles which can be seen in Figure 14 and Figure 15 have been defined. At the left y-axis the stroke of the actuator is displayed, which corresponds to the relative position of the actuator and its origin state.

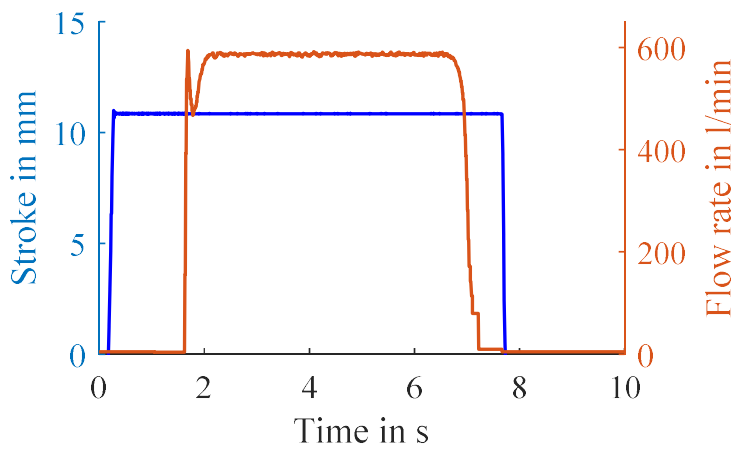

Figure 14: Switching process

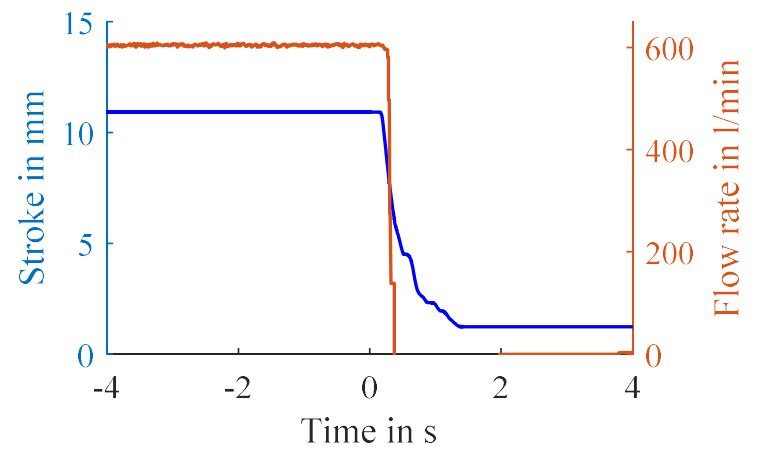

Figure 15: Reset process

In Figure 14 the test cycle for the investigation of the switching process and the static behavior is depicted. At the beginning of the test cycle the actuation system opens the valve abruptly. Since the servo valve is closed the actuation system always will switch the valve without applied pressure. After a defined time the servo valve is also opened and a flow rate can pass through the system. As the servo valve is opened rapidly a flow rate peak will occur. This will lead to high static and dynamic flow forces. As can be seen in Figure 14 the actuation system can hold the valve completely open even for flow rates up to $600 \mathrm{l} / \mathrm{min}$. To analyze the reset behavior of the actuation system while different flow rates were passing the valve the second test cycle according to Figure 15 was defined. At the beginning the valve is fully opened, by a defined time the solenoids and the relief system are turned off $(\mathrm{t}=0 \mathrm{~s})$.

\subsection{Switching process}

Switching times of common pilot operated valves are between $40 \mathrm{~ms}$ and $250 \mathrm{~ms}$ according to datasheets [19, 20]. An aimed switching time of $100 \mathrm{~ms}$ was defined for the novel electromechanical valve actuation system to be comparable to common pilot operated valves of nominal size 25. Multiple measurement series with different flow rates were conducted. During a measurement series the test cycle, explained before, was repeated 10 times. The measured stroke and current signal for the measurement series of 0 1/min (Figure 16 and Figure 18) and 600 1/min (Figure 17 and Figure 19) are displayed in the following graphs. The different measurements are shown in different colors.

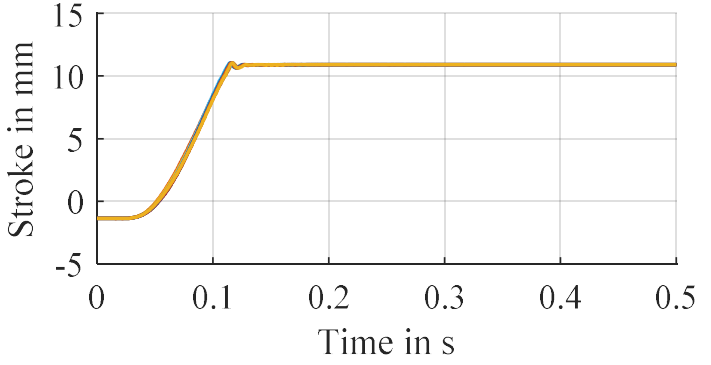

Figure 16: Stroke Signal for measurement series with $0 \mathrm{l} / \mathrm{min}$

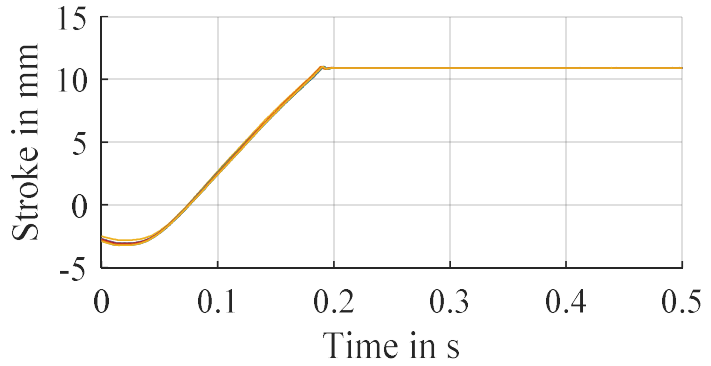

Figure 17: Stroke Signal for measurement series with $600 \mathrm{l} / \mathrm{min}$ 


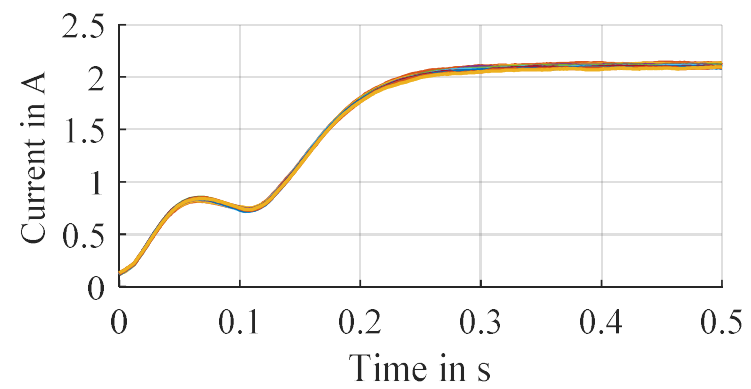

Figure 18: Current signal for measurement series with $0 \mathrm{l} / \mathrm{min}$.

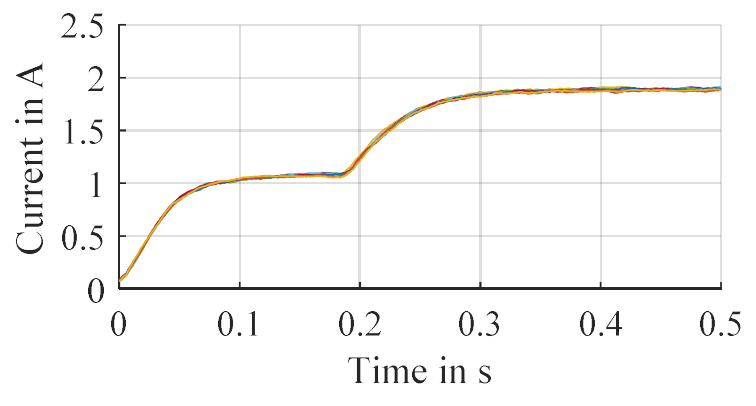

Figure 19: Current signal for measurement series with $600 \mathrm{l} / \mathrm{min}$.

The switching time of the actuation system during the measurement series with $01 / \mathrm{min}$ is around $130 \mathrm{~ms}$ as shown in Figure 15. During the movement the solenoid consumes a current of around $0.85 \mathrm{~A}$. Reaching the end stop the current drops down to $0.75 \mathrm{~A}$ due to counter induction. Afterwards the current increased to $2 \mathrm{~A}$. Since the valve switches while the servo valve is in closed position, there is no flow rate passing through the testing valve during the switching process. Therefore, the testing valve should switch under the same conditions, regardless of the flow rate which passes the valve when it is opened. As can be seen in the measurement results, the stroke curves as well as the current curves differ from each other. In the measurement cycle with $600 \mathrm{l} / \mathrm{min}$ the switching times increased up to nearly $200 \mathrm{~ms}$. Thereby the solenoid consumes a current of around $1 \mathrm{~A}$ and there is no decrease in the current signal like in the measurements with zero flow. Due to these differences there must be an effect of the high flow rate phase on the system's conditions during the switching process.

As a pressure is build up at the $\mathrm{T}$ port of the valve, a leakage flow over the sealing gap from the tank port to the pilot chamber develops. Therefore also the pressure in the pilot chambers increases. During the measurement cycle with $600 \mathrm{l} / \mathrm{min}$ a pressure between 1.5 and 2 bar was measured in the pilot chambers, which could explain the decreased performance by higher sealing friction forces compared to the measurement cycle with zero flow. Whereby the pressure in the pilot chambers was around 0 bar.

\subsection{Reset process}

Analyzing the reset times, the solenoids and the loading and unloading valve were deenergized while a flow rate was passing the valve. Again, multiple measurement series were conducted. Each series consists of 10 measurements evaluating the reset times during a given flow rate. The results of the stroke signal are displayed in Figure 20 and Figure 21. The measured pressures at the P and T port ( $\mathrm{p}_{2}$ and $\left.\mathrm{p}_{4}\right)$ are displayed in Figure 22 and Figure 23.

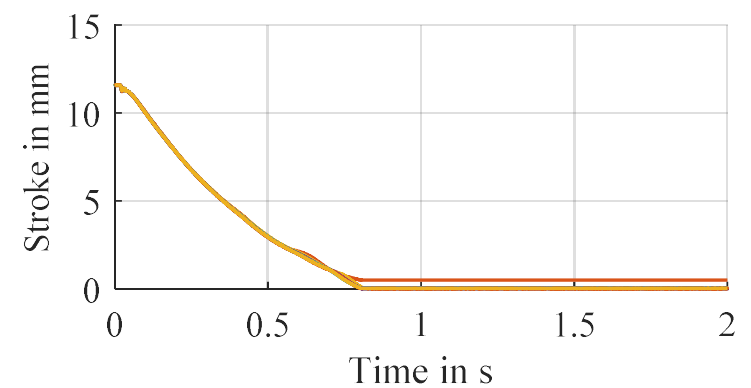

Figure 20: Stroke signal of reset process during a flow rate of $50 \mathrm{l} / \mathrm{min}$

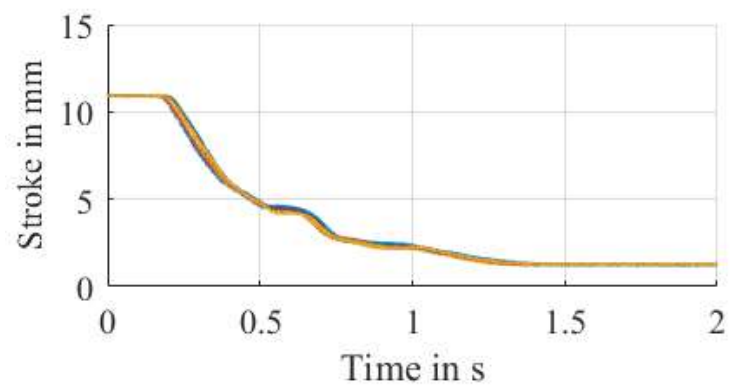

Figure 21: Stroke signal of reset process during a flow rate of $600 \mathrm{l} / \mathrm{min}$ 


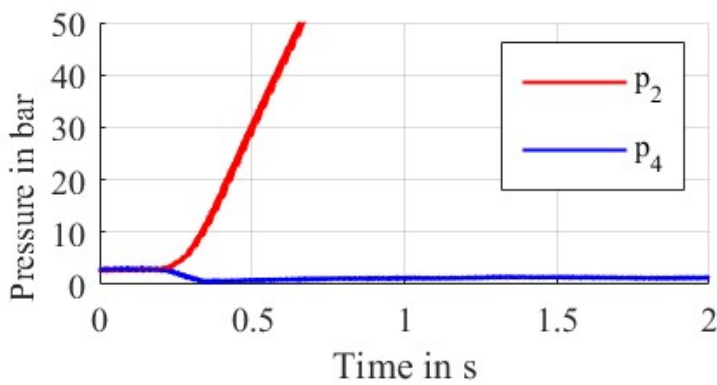

Figure 22: Pressure signal during the reset process with a flow rate of $50 \mathrm{l} / \mathrm{min}$

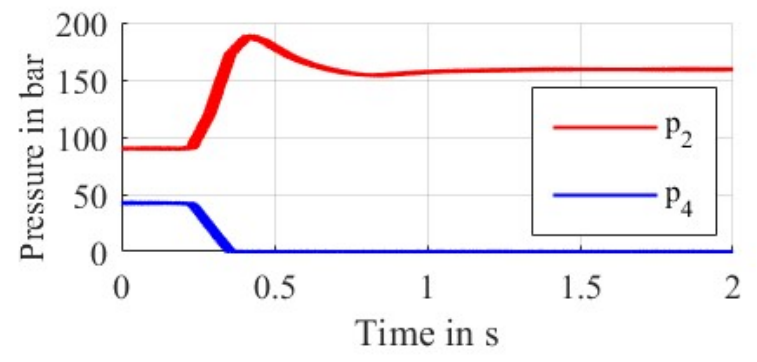

Figure 23: Stroke Signal for measurement series with $600 \mathrm{l} / \mathrm{min}$

As can be seen in Figure 20, the reset time of the relief cylinder and therefore also the cylinder rod during a flow rate of $50 \mathrm{l} / \mathrm{min}$ is approximately $750 \mathrm{~ms}$. Due to flow forces acting in closing direction and since there is no mechanical connection between the cylinder rod or the relief cylinder and the spool, the spool can move faster than the relief system. When closing the valve, the opening cross section is reduced, resulting in an increased pressure drop over the valve. Therefore, also the measurement results of the pressure signals $\mathrm{p}_{2}$ and $\mathrm{p}_{4}$ are displayed above. The safety-critical moment can be determined from the tank-sided pressure $\mathrm{p}_{4}$, at which the valve is completely closed with no pressure downstream of the valve. For both flow rates this point is reached after approximately $300 \mathrm{~ms}$. Considering the positive overlap of the metering edges of $5 \mathrm{~mm}$, pressure $\mathrm{p}_{4}$ should drop to 0 bar at a stroke of approximately $5 \mathrm{~mm}$. As flow forces are acting in closing direction they support the centering process of the spool and since they increase with small strokes it is likely that the valve spool tends to move faster than the relief cylinder. This can be especially observed in the measurement results of $600 \mathrm{l} / \mathrm{min}$, since the pressure drops to zero bar before the stroke signal reaches a position of $5 \mathrm{~mm}$.

Nevertheless, the relief system is still necessary. Without the relief system, the reset time would only depend on the flow forces. This would represent an issue, especially during phases with low flow rates and, since the deflected valve is nearly balanced in respect to the flow forces, also for large strokes. Friction forces may be larger than the flow forces and the spool would stay deflected. As can be seen in Figure 20 and Figure 22 the pressure $\mathrm{p}_{4}$ drops down to 0 bar nearly by the same time as reaching a $5 \mathrm{~mm}$ stroke. In this case, the relief system is primarily responsible for the centering of the spool and therefore the relief system is necessary during low flow rates. And as can been seen in the measurement cycle with a flow rate of 600 1/min (Figure 21 and Figure 23 the closing process is initiated by the relief system and then self-amplifying by the increased flow forces. During the initial $200 \mathrm{~ms}$, both pressures and stroke maintain their initial values. It is only after that time frame that the relief cylinder's stroke begins to decrease and shortly after the tank-sided pressure also drops. Therefore, it can be concluded that the closing movement is driven by the relief system.

\subsection{Switching under load}

Unlike previous measurements, the servo valve was opened before the test valve, which was thereby pressurized during the switching process. Therefore, the actuation system needed to overcome additional flow forces. The test cycle according to Figure 24 was repeated 10 times. The results of the flow rate (Figure 25), the stroke (Figure 26), the pressures (Figure 27) and the current of the active solenoid (Figure 28) over time are displayed below.

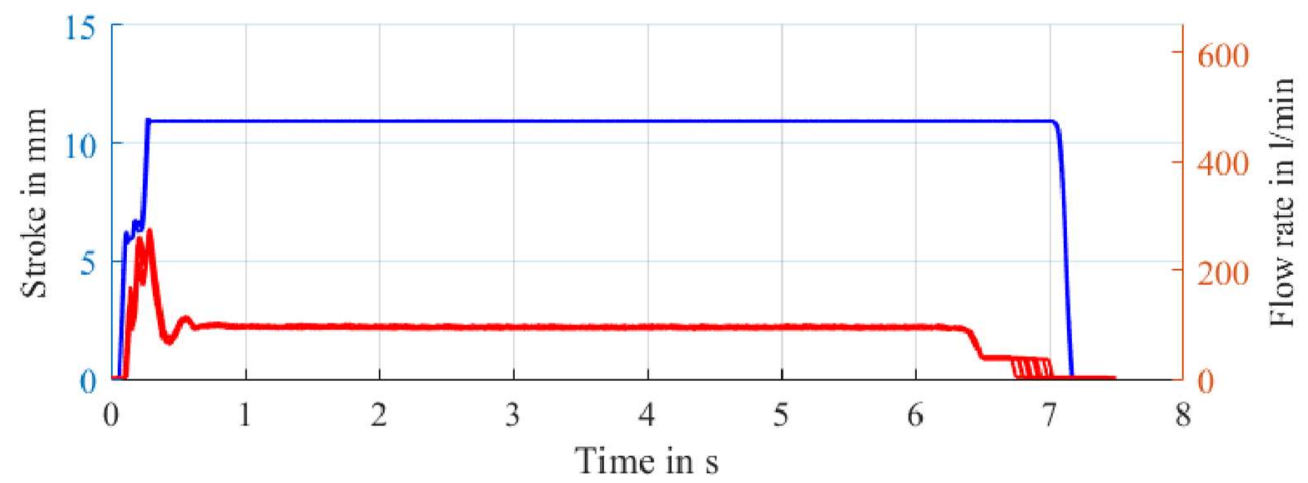

Figure 24: Measurement cycle for switching under pressure 


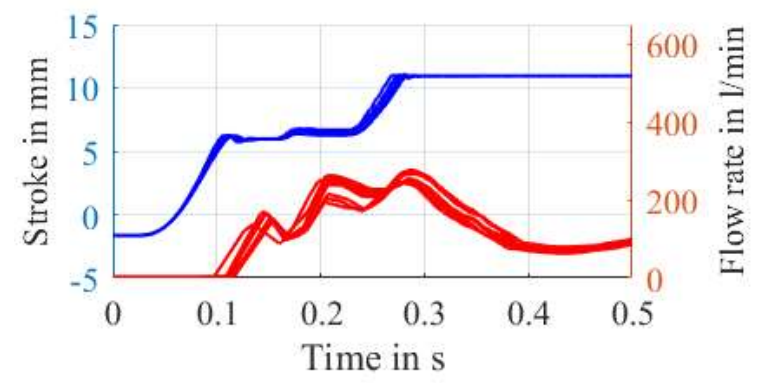

Figure 25: Flow rate with applied 100 bar and $100 \mathrm{l} / \mathrm{min}$

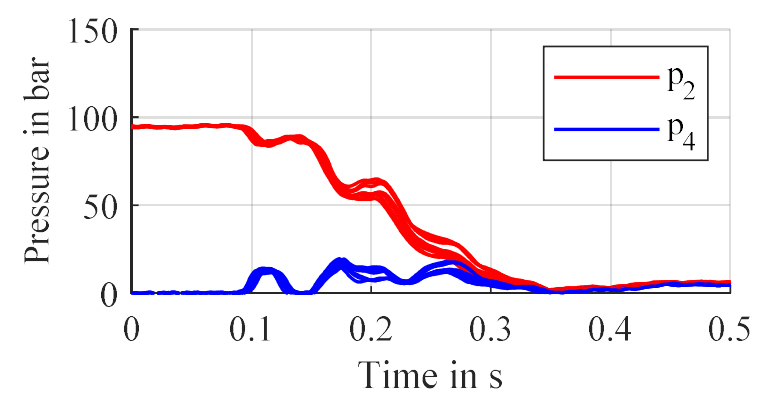

Figure 27: Pressure signal with applied 100 bar and $100 \mathrm{l} / \mathrm{min}$

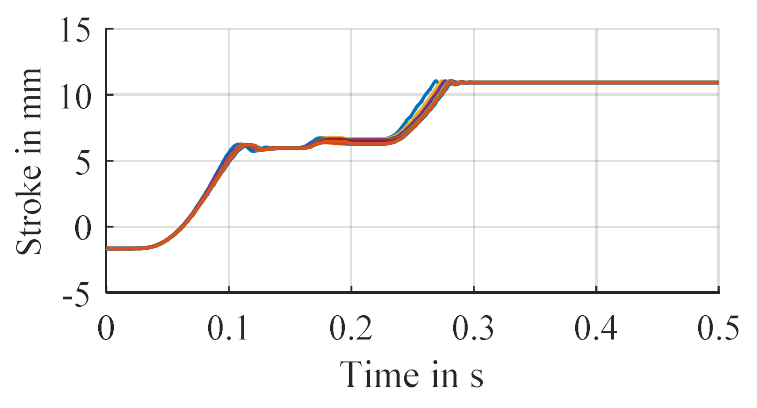

Figure 26: Stroke signal with applied 100 bar and $100 \mathrm{l} / \mathrm{min}$

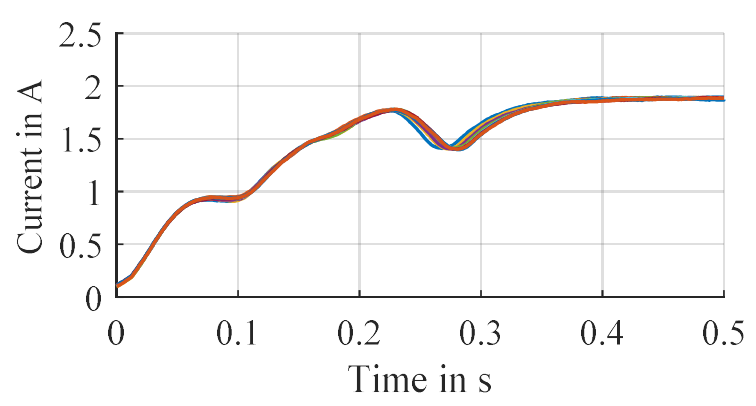

Figure 28: Current signal with applied 100 bar and $100 \mathrm{l} / \mathrm{min}$

The system was supplied with a flow rate of $100 \mathrm{l} / \mathrm{min}$ and a pressure of $100 \mathrm{bar}$. The valve was operated in a constant pressure system, during which a flow rate peak of $250 \mathrm{l} / \mathrm{min}$ occurred. The thereby resulting flow force tends to close the spool. Compared to the stroke signal with no flow rate, a large plateau in Figure 26 can be identified between 0.1 and $0.25 \mathrm{~s}$. During this phase, the force applied by the actuator is in an equilibrium with the flow force. The spool remains in the corresponding position until the flow rate decreases, so the actuation system can overcome the flow force. The gap of the metering edge has only a small opening, as can be seen in the stroke signal (considering the $5 \mathrm{~mm}$ positive overlap). At this point of operation, the flow rate is determined by the pressure drop over the valve. Since the occurring flow rate (up to $2501 / \mathrm{min}$ ) is larger than the adjusted flow rate of $100 \mathrm{l} / \mathrm{min}$, the pressure before the valve starts dropping (Figure 27) during this operation. As the spool starts moving again, the pressure difference over the valve is reduced to a comparatively low value. Also, the current signal is significantly increased during the time range of 0.1 to $0.25 \mathrm{~s}$. During this phase, power consumption compared to the previous measurements is increased and therefore higher forces are applied by the actuator. It can be assumed that the solenoid is applying maximum nominal force as the current nearly reaches the nominal value of approximately $2 \mathrm{~A}$. The short-time reduced current demand at $0.28 \mathrm{~s}$ is due to the velocity-dependent counterinduction, which occurs when the solenoid armatures reaches its end position.

\section{Discussion}

The designed concept, which uses solenoid actuators, is able to realize strokes of around $11 \mathrm{~mm}$ with switching times of between $130 \mathrm{~ms}$ and $200 \mathrm{~ms}$. It is therefore competitive with conventional pilot operated valves which achieve switching time between $40 \mathrm{~ms}$ and $250 \mathrm{~ms}$. Nevertheless, the designed concept needs further improvement, since occurring internal leakage may affects the actuator's performance.

With regard to the reset times, the actuation system is not comparable with common valves, as these achieve considerably shorter reset times. Geometrical optimizations and adapted springs need to be implemented in order to improve the reset time. Even if the designed actuation system reaches reset time of $750 \mathrm{~ms}$, they still can be reduced. It is noticeable that the flow supported spool is even faster at returning to the middle position than the relief system in test cycles with high flow rates. Nevertheless, hence a flow supported centering of the spool cannot be guaranteed, it is necessary to actively initiate the self-amplifying reset process, especially if low flow rates are passing the valve.

Although the concept has been adapted to an operation in a flow-controlled system where the pump is completely swung back during the switching process, existing systems may be few. Therefore, the switching process also was investigated while the valve was pressurized. The actuation system was used to switch the spool while a flow rate of $100 \mathrm{l} / \mathrm{min}$ was applied with a maximum pressure of $100 \mathrm{bar}$. In this case, switching times of approximately 
$250 \mathrm{~ms}$ were achieved. A time interval, during which the stroke signal was indifferent, suggests no movement of the spool. During that period of time, the acting flow forces in closing direction are in balance with the actuator force. Flow forces at this stage are high, due to the initially occurring flow rate peak. As the pressure before the valve decreases and the flow rate stabilizes, the flow forces decrease subsequently allowing the actuator force to accelerate the spool until reaching its full stroke. The application of the actuation system therefore is not limited to flow controlled systems. However, it should be considered that the switching performance and whether the actuation system can switch the valve is dependent on the hydraulic system and the operation condition.

As in measurements up to now the relief system was supplied by a separate hydraulic circuit the integration into a large hydraulic circuit as depicted in Figure 12 should be analyzed in further research.

\section{Conclusion}

As experiments on the concept show, the designed novel hydraulically relieved electromechanical direct actuation system for large scale switching valves is feasible. Switching times of around $200 \mathrm{~ms}$ and reset times of around $750 \mathrm{~ms}$ are achievable. The application of such a concept is particularly useful for systems, in which the main line pressure can drop below a critical value of 4 bar and therefore, an internal supply of the pilot valve is not possible. However, the hydraulic spring relief system needs to be controlled, therefore the integration into the main hydraulic system must be realized, exemplarily shown in Figure 12. Compared to common pilot operation systems, the dependency between the energy provision to overcome the spring forces and to accelerate the spool is resolved. Thus, the main pump can be used to compress the centering springs by supplying the relief system independently from the valve's switching process. Since the requirements for the actuation forces to shift the spool have been drastically reduced by the relief system, alternative applications of electromechanical actuators are possible.

The concept of a hydraulic spring relief system, which is embedded into an electromechanical valve actuation system, opens up new prospects for actuator implementations. Nevertheless, the design must be matched to the respective system operation profile. If the application in a constant pressure system is planned, the force of the electromechanical tranformator needs to be adapted to the occurring flow forces.

\section{Acknowledgments:}

The IGF research project 20084/N of the research association Forschungskuratorium Maschinenbau e. V. - FKM, Lyoner Straße 18, 60528 Frankfurt am Main was supported from the budget of the Federal Ministry of Economic Affairs through the AiF within the scope of a program to support industrial community research and development (IGF) based on a decision of the German Bundestag.

\section{Conflicts of Interest:}

The authors declare no conflict of interest.

\section{References}

[1] G. Bauer, Ölhydraulik: Grundlagen, Bauelemente, Anwendungen: Vieweg + Teubner, 2009.

[2] W. Backé and W. Hahmann, Grundlagen der Ölhydraulik: Umdr. zur Vorlesung: Institut für hydraulische und pneumatische Antriebe und Steuerungen der RWTH (IFAS), 1972.

[3] J. Watton, Fundamentals of Fluid Power Control. Cambridge: Cambridge University Press, 2009.

[4] Hydraulic fluid power - Four-port directional control valves - Mounting surfaces, ISO 4401, International Organization for Standardization, Berlin, Jul. 2005.

[5] Hydac International, HYDAC Fluidtechnik: Industrial Valves (accessed: Apr. 21 2021).

[6] E. Kauffmann, Hydraulische Steuerungen. Wiesbaden: Vieweg+Teubner Verlag, 1980. [Online]. Available: http://dx.doi.org/10.1007/978-3-322-85723-1

[7] N. Herakovič, J. Duhovnik, and M. Šimic, "CFD simulation of flow force reduction in hydraulic valves," Tehnički vjesnik - Technical Gazette, vol. 22, no. 2, pp. 453-463, 2015, doi: 10.17559/tv-20141128090939.

[8] K. Schrank and H. Murrenhoff, "Beschreibung der Strömungskraft in Längsschieberventilen mittel Impulserhaltung," O+P Journal, no. 4, pp. 4-15, 2013.

[9] Helmut Tatar, Störkräfte bei elektromagnetisch betätigte Wegeventilen. Aachen, 1974.

[10] W. Backé and H. Tatar, Untersuchung des Einflusses von Störkräften auf den Schaltvorgang bei Wegeventilen der Hydraulik. Opladen: Westdt. Verl., 1975.

[11] G. Schuster, CFD-gestützte Maßnahmen zur Reduktion von Strömungskraft und Kavitation am Beispiel eines hydraulischen Schaltventils. Aachen: Shaker, 2005.

[12] N. Gebhardt and J. Weber, Hydraulik - Fluid-Mechatronik: Grundlagen, Komponenten, Systeme, Messtechnik und virtuelles Engineering: Springer Berlin Heidelberg, 2020. 
[13] H. Watter, Hydraulik und Pneumatik: Grundlagen und Übungen - Anwendungen und Simulation: Vieweg+Teubner Verlag, 2008. Accessed: Jan. 262021.

[14] T. Vonderbank and K. Schmitz, "Design of Electromechanical Actuators for Large Sized Valves," Proceedings, vol. 64, no. 1, p. 37, 2020, doi: 10.3390/IeCAT2020-08477.

[15] ISO, "Fluid power systems and components - Graphic symbols and circuit diagrams: Part 1: Graphic symbols for conventional use and data-processing applications (ISO 1219:2012 + Amd.1:2016)," vol. 2012.

[16] P. Bordovsky, K. Schmitz, and H. Murrenhoff, "CFD Simulation and Measurement of Flow Forces Acting on a Spool Valve," in 10TH INTERNATIONAL FLUID POWER CONFERENCE, 2016, pp. 473-484.

[17] P. Bordovsky, Evaluation of steady-state flow forces in spool valves: = Evaluierung stationärer Strömungskräfte in Schieberventilen, 1st ed. Düren: Shaker Verlag, 2019.

[18] N. D. Manring and S. Zhang, "Pressure Transient Flow Forces for Hydraulic Spool Valves," Journal of Dynamic Systems, Measurement, and Control, vol. 134, no. 3, p. 193, 2012, doi: 10.1115/1.4005506.

[19] Parker Hannifin GmbH, Directly operated and pilot operated directional control valves: Series DIVW / $\mathrm{D} 1 \mathrm{DW} / \mathrm{D} 3 \mathrm{~W} / \mathrm{D} 3 \mathrm{DW} / \mathrm{D} 31 \mathrm{DW} / \mathrm{D} 41 \mathrm{VW} / \mathrm{D} 81 \mathrm{VW} / \mathrm{D} 91 \mathrm{VW}$ (accessed: Apr. 212021 ).

[20] Bosch Rexroth, Directional spool valves, pilot-operated, with hydraulic or electro-hydraulic actuation: type WEH and WH (accessed: Apr. 212021 ). 